Anuario del Instituto de Historia Argentina, diciembre 2018, vol. 18, n² 2, e076. ISSN 2314-257X Universidad Nacional de La Plata

Facultad de Humanidades y Ciencias de la Educación

Centro de Historia Argentina y Americana

\title{
Educación en tiempos de la Confederación Argentina
}

José Bustamante Vismara

Universidad Nacional de Mar del Plata, Argentina jovisma@ hotmail.com

Cita sugerida: Bustamante Vismara, J. (2018). Educación en tiempos de la Confederación Argentina. Anuario del Instituto de Historia Argentina, 18 (2), e076. https://doi.org/10.24215/2314257Xe076

Recibido: 08 marzo 2018 - Aceptado: 18 julio 2018 - Publicado: 07 diciembre 2018

(1) (2) (2) Esta obra está bajo licencia Creative Commons Atribución-NoComercial-CompartirIgual 4.0 Internacional cc) (1) $\mathrm{http}: / /$ creativecommons.org/licenses/by-nc-sa/4.0/deed.es_AR 


\title{
Educación en tiempos de la Confederación Argentina
}

\section{Education in times of the Argentine Confederation}

José Bustamante Vismara

Universidad Nacional de Mar del Plata, Argentina

jovisma@hotmail.com

\section{Resumen:}

Este análisis indaga en dos facetas de la política educativa desarrollada bajo el gobierno de la Confederación Argentina en la década de 1850. Por un lado se recuperan rasgos del proyecto alberdiano, sus modulaciones al formularse el artículo quinto de la Constitución de 1853, así como las notas introducidas por la reforma de 1860. Luego se estudian aspectos fiscales y educativos de ese gobierno. Con este propósito se atiende a legajos de órdenes de pago del Departamento de Justicia, Culto e Instrucción Pública durante el período comprendido entre 1856 y 1860.

Palabras ClaVe: Confederación Argentina, Historia de la Educación, Constitución, Finanzas.

\begin{abstract}
:
This paper searches two facets of the educational policy developed under the government of the Argentine Confederation in the 1850s. On one hand, traces of the Alberdian project are recovered, their modulations in the formulation of the fifth article of the constitution of 1853, as well as the notes introduced by the reform of 1860. Later we study fiscal and educational aspects of that government; the payment orders of the Department of Justicia, Culto e Instrucción Pública during the period between 1856 and 1860 are analyzed for that purpose.
\end{abstract}

KEYWORDS: Argentine Confederation, History of Education, Constitution, Finance.

En la década de 1850 se sucedieron significativas experiencias educativas. Éstas, articuladas con los procesos sucedidos en las primeras décadas postindependientes, fueron neurálgicas en la configuración del sistema educativo argentino. Esta afirmación supone desandar -y revisar- algunos de los presupuestos con que usualmente se atiende a la historia de la educación argentina.

Tras una contextualización en torno al marco historiográfico en que se inscribe el análisis, se indaga en dos facetas de la política educativa desarrollada bajo el gobierno de la Confederación Argentina. Por un lado, se recuperan rasgos del proyecto alberdiano, sus modulaciones al formularse el artículo quinto de la Constitución de 1853, así como las notas introducidas por la reforma de 1860. Con ello se esperan reconocer rasgos que no serían modificados con la ley 1420. La hipótesis que aquí se afirma indica que el artículo quinto de la Constitución de 1853 -que delegó en las provincias la organización de la educación primaria- ${ }^{1}$ cobró sentido tanto a partir de las experiencias educativas previas a la redacción del texto constitucional, como desde las que entonces sucedieron. Dicho de otro modo, ese artículo quinto no se fundaba en un vacío de referencias, ni caería en el olvido tras la experiencia confederal. Además se agregan algunas notas acerca de la importante modificación que sobre éste se efectuaron en la constituyente porteña.

Luego se estudian aspectos fiscales y educativos del gobierno de la Confederación. Se buscará trazar una cartografía de la educación ligada a la Confederación Argentina a partir del análisis de documentación generada por el Departamento de Justicia, Culto e Instrucción Pública. Con este propósito se atenderá a legajos de órdenes del período comprendido entre 1857 y 1860.

Las dos partes que estructuran el trabajo indagan en rasgos bien distintos, pero el conjunto se articula al tratar de comprender aspectos de la política educativa puesta en marcha hacia 1850. 
¿Qué es lo que se ha reflexionado acerca de la educación en el período? A mediados del siglo XX Antonino Salvadores fue uno de los autores que más había trabajado por reconocer el horizonte educativo de mediados del siglo XIX. De hecho, uno de sus libros interroga qué sucedió después de Caseros con la educación pública. Al responder al interrogante ofrecía una imagen centrada en Buenos Aires, y apuntaba algunas notas marginales sobre lo ocurrido en la Confederación (Salvadores, 1940). Tales indicaciones, mayormente, se articulaban a un trasfondo nacionalista, se fundaban en rasgos prescriptivos, o bien se presuponían aspectos que no eran problematizados. Así, por ejemplo, consideraba "natural que los primeros actos del Gobierno provisorio fuesen dirigidos en el sentido de restituir las instituciones al estado en que se encontraban en el momento de iniciarse el largo interregno de la dictadura"; o bien identifica al unitarismo como un cuerpo doctrinal representado, por ejemplo, con Valentín Alsina a quien reconocía como un unitario del año 1822 (Salvadores, 1940, p. 9). Como complemento de estos planteos cabe referir a la lectura política y social que en forma contemporánea se efectuaba sobre la Confederación. Las perspectivas aludían a lo sucedido durante este gobierno como un lapso de vacío institucional, o bien de esfuerzos afirmados en la personalidad de Urquiza que - no obstante su capacidad- no lograron consolidar una suficiente maduración institucional. Entre estos puede aludirse a los trabajos de Beatriz Bosch y su énfasis en la capacidad de Urquiza como organizador (1963), o bien al libre de Haydée Gorostegui Torres (1972).

En los últimos años se han puesto en tensión estas miradas sobre el período y se le ha dado una renovada complejidad al modo en que se interpreta lo sucedido en esta década. Al respecto, cabe destacar el análisis de Pablo Buchbinder (2002) sobre la sesión de atribuciones militares y la reestructuración aduanera y comercial sucedida con el paso de los estados provinciales al estado nacional; la investigación que realizó Juan Carlos Garavaglia (2010) sobre la fiscalidad confederal de la década del 1850; el estudio de Ana Laura Lanteri (2015) sobre el funcionamiento del congreso y la justicia de la Confederación. Cada uno de éstos, con lógicas diferentes, ofrecen un panorama de los modos en que ha modulado en los últimos años la historiografía del período. Pero entre esta renovación y lo sucedido en el ámbito educativo abundan los interrogantes. Los trabajos de María Fernández (2000/2001), Susana Schoo (2009; 2014), Nancy Escobar (2010), Alejandro Herrero (2010), Carlos Newland (2014), Daniel Duarte (2015), Marcelo Caruso y Marco Rodríguez Wehrmeister (2018) han avanzado en distintas líneas sobre la temática, aunque fundamentalmente lo han hecho reconociendo lo sucedido en los colegios nacionales, sobre lo acontecido tras $1862 \mathrm{o}$ bien atendiendo a Buenos Aires.

En este panorama, entonces, cobran sentido distintas preguntas sobre el desarrollo educativo de la Confederación a lo largo de la década de 1850. Dos asuntos serán analizados en este texto: se trabajará sobre el diseño constitucional ligado a la temática; así como se llevará adelante una descripción de las erogaciones del estado confederal en el ámbito educativo. Con ellos se espera ofrecer un horizonte que aporte complejidad al análisis del período, así como se busca atender aspectos que, al ser opacados, generan malinterpretaciones sobre el devenir del desarrollo histórico y educativo de Argentina.

\section{Constitución, EDUCACión Y ESTADO: LA ESTELA DE LAS CONSTITUYENTES}

Cuando los trabajos de historia de la educación se detienen por lo sucedido a mediados del siglo XIX, las referencias insoslayables se afirman en las propuestas de Domingo Faustino Sarmiento, Juan Bautista Alberdi y, quizás, Bartolomé Mitre. Sin dudas, motivos sobran para justificar tal detenimiento y acompañarlo con las propuestas impulsadas por Marcos Sastre, Juana Manso, José Manuel Estrada, Amadeo Jacques, entre otros. Al decir de Tulio Halperín Donghi, aquellos letrados formaron parte de una encumbrada de elite clarividente (1982). Un grupo de intelectuales que durante el ocaso del rosismo reflexionó acerca de distintos proyectos de construcción estatal y, singular caso en la historia americana, tuvo la oportunidad de ponerlos en marcha.

No es el propósito de este artículo describir esos proyectos. De hecho, abundan los análisis sobre la temática que se detienen con exhaustividad en sus reconstrucciones; entre otros pueden citarse los trabajos 
de Torcuato Di Tella (1969) o Juan Carlos Tedesco (2009). Pero dado el impacto que tendrían las Bases de Alberdi en el texto promulgado en 1853, sí interesa referirlo con algún detalle. Allí, tras considerar que el republicanismo era un proceso dado y afirmado, el autor ofrece un panorama de cada una de las cartas magnas promulgadas en la región en las décadas precedentes. Expresa que para Argentina un grado de republicanismo restringido sería el medio más adecuado "a las exigencias de la edad y del espacio" (1915, p. 75). Y acerca de lo educativo afirma la interpretación que distingue a la educación de la instrucción. Ésta, espontánea y multiplicada sin mediar instituciones; la primera conducida y dirigida mediante un plan. En complemento a ello consideraba que la instrucción llegaría gracias a la emulación de los inmigrantes europeos, mientras que la educación debería estimularse a través de escuelas de aplicación y de acciones concretas impulsadas por la acción industrial o mercantil. Así, no faltan alusiones de Alberdi a las universidades de América del Sud como "fábricas de charlatanismo, de ociosidad, de demagogia y de presunción titulada" (1915, p. 77-78). En conjunto, refuta la tesis que supone la consolidación del orden social a partir de la educación e indica que se alcanzarían los hábitos de orden y la buena educación "a través del influjo de masas" (1915, p. 91).

El proyecto de constitución que cierra la segunda edición del libro sería, en buena medida, tomado como borrador para el texto promulgado en Santa Fe en $1853^{2}$. Alberdi se encargó de hacer circular esos ejemplares enviándolos a la prensa rioplatense y a políticos prominentes, entre otros, claro está, a Justo José de Urquiza. Éste, en febrero de 1852, había triunfado sobre Juan Manuel de Rosas en la batalla de Caseros. Firmados el Protocolo de Palermo y el Acuerdo de San Nicolás, en abril y mayo respectivamente, las provincias signatarias acordaron delegar en forma provisoria las facultades ejecutivas del gobierno de la Confederación a Urquiza, así como convocar a un congreso constituyente. Durante ese agitado año de 1852, los legisladores porteños rechazaron los términos del Acuerdo de San Nicolás que había firmado Vicente López y Planes -que fungía provisoriamente como gobernador de Buenos Aires- y provocaron una nueva intervención de Urquiza: se disolvió la Sala de Representantes y se expulsó a varios dirigentes. El día 8 de septiembre Urquiza y el grueso de sus tropas dejaron Buenos Aires para sumarse al congreso constituyente que se reuniría en Santa Fe, y tan sólo tres días demoraron los porteños en agitar una renovada revolución. El 11 de septiembre de 1852 se volvió a reunir la sala de representantes y se eligió al general Pinto como gobernador interino (Scobie, 1964). La objeción de la dirigencia porteña -en la que se articulaban actores con trayectorias políticas heterogéneasobservaba las atribuciones que se asignaban al ejecutivo nacional. El fondo del problema, sin embargo, era la resistencia a una unificación nacional que ellos no controlarían con el esquema de representación propuesto dos constituyentes por provincia-, y cuyas consecuencias podrían recaer en la pérdida del manejo de recursos militares y fiscales, es decir, de las rentas de la aduana porteña. Urquiza, al frente del mando militar de la Confederación, consideró la posibilidad de volver a avanzar sobre Buenos Aires, pero optó por dejar a la provincia "en el pleno goce de sus derechos" (Scobie, 1964, p. 61). Se iniciaba así el enfrentamiento entre la Confederación Argentina y el Estado de Buenos Aires.

En ese contexto, el texto de Alberdi cobraría un lugar relevante. Sus lineamientos marcarían una huella de la cual los constituyentes reunidos en Santa Fe poco se apartarían; sin embargo, en materia educativa sí hubo significativas diferencias. El artículo quinto que allí se redactaría y que sería tan significativo para el devenir educativo argentino no hunde sus raíces en las expresiones que las Bases formularon acerca de la instrucción o educación. Y tampoco se expresan en el borrador de Alberdi las atribuciones que tendría el congreso en el dictado de planes de instrucción general y universitaria (en la Constitución de Santa Fe serían asentados en el art. 64, inc. 16) ${ }^{3}$. Sí, en la versión alberdiana figuran los denominados "derechos de libertad” y se expresa la "libertad de enseñar y aprender". Asimismo en el preámbulo de la versión de Valparaíso se destacaría entre las atribuciones del "estado federativo" el aliento a la "educación popular" (Alberdi, 1915, p. 258), pero en el articulado no se refieren aspectos sobre la temática.

¿Cómo fue redactado, entonces, el artículo quinto? El trabajo de Héctor Bravo sobre las bases constitucionales de la educación argentina vincula a la Constitución de 1853, lo educativo y distintos modelos constitucionales (Bravo, 1988). Pero al precisar los antecedentes del artículo quinto, Bravo refiere 
dos fuentes: la Constitución Mexicana de 1824 y la constitución propuesta en el seno del Congreso Constituyente rioplatense de 1826. Efectivamente, la Constitución mexicana de 1824 aludía, en su artículo 50, inciso 1, que el estado federal promovería la ilustración. Pero Bravo no aclara que allí la educación sí era delegada a cada uno de los estados que integraban la federación, y éstos -en varios casos- la dejaban en manos de las municipalidades. Sin embargo, la propuesta de constitución rioplatense de 1826 en su artículo 143 delegaba la administración de la educación primaria en las provincias -aunque, ya es sabido, era centralista en aspectos neurálgicos como la designación del poder ejecutivo de las mismas-. Se trata, entonces, de dos pistas que resultan algo equívocas para considerarlas antecedentes del artículo quinto.

Hacia 1850, además del conflicto entre la Confederación Argentina y el estado de Buenos Aires, en el seno del gobierno urquicista se puso en marcha un proceso de organización institucional. A través de una compleja relación, los hasta entonces estados provinciales - entidades autónomas y soberanas que, al decir de José Carlos Chiaramonte (1993), conformaron entre 1820 y 1852 una "débil Confederación"- cedieron al estado federal algunas de sus atribuciones. Pablo Buchbinder (2002) ha descripto los cambios sucedidos en el terreno militar y en la política comercial y aduanera para el caso de Corrientes. Evidentemente aquél fue un caso muy significativo, dada las experiencias correntinas en las décadas previas (con los gobiernos de Pedro Ferré y los reiterados enfrentamientos al Buenos Aires rosista). Y, sin embargo, hubo en estos años un proceso de desmilitarización y de cesión de derechos financieros. Entonces, si la construcción del estado nacional requería la delegación de facultades de los estados provinciales a la nación (finanzas, relaciones exteriores, atribuciones militares, etc.), ¿por qué los constituyentes de Santa Fe sostuvieron la educación elemental bajo la dirección de las provincias?

Una de las claves que explicaría tal decisión habría estado en las discusiones del Congreso General Constituyente reunido entre fines de 1852 y 1854 . Posiblemente allí el tema se haya tratado, pero las actas de esa reunión tienen limitaciones. Puntualmente la lógica del constituyente funcionó con trabajos en comisiones hasta abril de 1853, momento en que comenzó a discutirse el articulado del borrador de la carta magna. En la reunión del 23 de abril se trató el artículo quinto. Pero al iniciar esa sesión se modificó el registro de las discusiones en virtud de la extenuación que manifestaron los taquígrafos de la incipiente estructura burocrática. Así, justamente antes de que se tratara el artículo quinto, los legisladores sostuvieron que a estos transcriptores "no podía exigírsele tampoco mas de aquello á que alcanzasen sus fuerzas atendidos los pocos elementos de que disponía la Secretaría” (Ravignani, 1937, p. 503). Se reproducen, desde entonces, una escueta información de las intervenciones. Acerca del artículo quinto se indica:

Se puso en discusión el artículo $5^{\circ}$.

Después de ligeras observaciones y explicaciones que pidieron los Señores Zenteno y Seguí y que fueron satisfechas por los miembros informantes de la Comisión, se votó y resultó aprobado por unanimidad (Ravignani, 1937, p. 506).

Y, en lo que respecta al constituyente de Santa Fe, allí se pierde la estela del asunto. El texto finalmente sancionado es conocido. Cada provincia dictaría su constitución bajo un sistema representativo republicano -y acorde a la Constitución Nacional-. Ese régimen debería asegurar la administración de la justicia, el régimen municipal y, lo que aquí interesa, la "educación primaria gratuita”.

Dos rasgos caben destacarse de ese artículo: tanto la referencia a la gratuidad como la reafirmación en manos de las provincias de la educación elemental resultan significativas. Con el proyecto de Alberdi hay vínculos y tensiones. Éste fue sucintamente referido párrafos atrás (y reiteradas veces recitado, a veces esquemáticamente, en los trabajos de la disciplina). Lo que finalmente sería el artículo quinto del texto de Santa Fe no estaba en las Bases. El proyecto que allí incluyó Alberdi tenía entre sus artículos cuarto, quinto, sexto y séptimo alusiones a las provincias y al sistema republicano, a la integridad del territorio, a la soberanía y paz interior, a las intervenciones que podría llevar adelante la Confederación, al vínculo entre las constituciones provinciales y la general, pero allí no se aludía a lo educativo, ni a la instrucción pública. Donde Alberdi sí refería a la instrucción (y no a la educación, o a la educación primaria) era en el 
artículo 32 de su proyecto -incluido dentro de las Garantías públicas de orden y de progreso-. Ese texto expresa: "La Constitución asegura en beneficio de todas las clases del Estado la instrucción gratuita, que será sostenida con fondos nacionales destinados de un modo irrevocable y especial a ese destino". ¿Qué suponía la implementación de una "instrucción gratuita"? Fundado en el modo en que diferenció la instrucción de la educación, resulta sensato considerar que ésta no parecería vincularse a un sistema de educación primaria en manos del estado -la educación popular, al decir de Sarmiento-. Entonces, el estado sí debería vincularse con el fomento de los progresos intelectuales, científicos, morales y agrícolas, pero la educación elemental no estaba entre sus objetivos prioritarios.

Pero el problema también puede ser analizado desde otro punto de vista inverso: si la vocación centralizadora acompañó la sanción de la Constitución -con el avance del estado federal sobre facultades antes reservadas a los estados provinciales-, ¿ por qué no se desplegó sobre lo educativo? Quizás, la explicación del asunto se encuentra en las experiencias de los estados provinciales en la materia durante las décadas previas. Se ha mostrado en otros trabajos que en las primeras décadas del siglo se llevaron intensos y ricos procesos institucionales ligados a las escuelas estatales (Bustamante Vismara, 2016). Aunque, tal referencia, también podría efectuarse acerca de las milicias, la justicia o la fiscalidad y, sin embargo, en estos terrenos el estado federal sí se abrogó atribuciones (Buchbinder, 2002).

El segundo rasgo que resulta llamativo se vincula a la gratuidad. Y si es poco lo que puede decirse al respecto en relación a la constituyente de Santa Fe, o acerca de la referencia que se citó de Alberdi, no resulta menos significativo atender a lo sucedido en 1860. Sabido es que tras la secesión del estado de Buenos Aires y la batalla Cepeda, Buenos Aires comenzó su unificación al estado federal con la potestad de revisar el texto constitucional de la Confederación. Así se estableció en el pacto de San José de Flores del 11 de noviembre de 1859.

La asamblea constituyente bonaerense fue integrada por casi cincuenta miembros. Un número sustancialmente mayor que los 14 constituyentes que formaron parte de la reunión de Santa Fe. Tras varias semanas de reuniones preparativas, en la sesión del 25 de abril de 1860 se puso en discusión el plan de reformas (Ravignani, 1937, p. 765 y siguientes). Lo relativo a la educación fue analizado como parte del primer grupo de cuestiones -ligadas a las declaraciones, derechos y garantías-, y la comisión abocada a su indagación fue conformada por Bartolomé Mitre, Dalmacio Vélez Sarsfield, José Marmol, Antonio Cruz Obligado y Domingo F. Sarmiento. Oportunamente, fue Vélez Sarsfield quien informó a la asamblea los cambios que sugerían para el artículo quinto (Ravignani, 1937, p. 808). El nudo de su exposición -y posterior discusión - estuvo centrado en torno a la supresión de la posibilidad de revisar las constituciones provinciales por parte del Congreso nacional. La justificación de tal cambio no estuvo apuntalada en una vocación de autonomía; se señaló que si hubiera leyes inconstitucionales en las cartas provinciales, sería una eventual decisión del Supremo Tribunal de Justicia quien debería observarlas. No el Congreso. El cambio se aprobó por 26 votos contra 19 (Ravignani, 1937, p. 809). Pero también se alteró lo referente a la gratuidad de la enseñanza primaria. Sarmiento, apenas promulgada la carta de Santa Fe, había expresado una opinión que luego prevalecería en la constituyente de Buenos Aires. En 1853, todavía residiendo en Chile, escribió sus Comentarios a la Constitución (Sarmiento, 1895). Allí pondera la referencia a la "educación gratuita" como uno de los puntos más "bellos" de la carta promulgada en Santa Fe -“y con la que se ha puesto de un golpe á la altura de su época”-, pero advierte problemas en su posible implementación (1895, p. 236). Al prescribir la gratuidad se determinaba que no se cobraría a los alumnos estipendio alguno. Ahora bien, reflexionaba, si las provincias a las que se les delegaba tal potestad no tenían fondos, ¿quién financiaría? En su perspectiva eran los propios vecinos que se debían comprometer junto al estado. Y así se reafirmó en las sesiones de la Convención del estado de Buenos Aires a principios de 1860 cuando se indicó que prescribir la gratuidad impediría el apoyo de las comunidades locales. Cuando en Buenos Aires, justamente el estado que mayor desarrollo tuvo en tal sentido, los mayores logros se habrían alcanzado "llamando al pueblo á concurrir a los gastos de la educación” (Ravignani, 1937, p. 773). En adición a este argumento se anotó que la mentada 
gratuidad era "falsa" dado que, de uno u otro modo, los gastos que cubriría el servicio serían provistos por el tesoro público.

En suma, así, finalmente, quedó redactado el artículo quinto:

\begin{tabular}{|l|l|}
\hline Constitución de 1853 & Reforma de 1860 \\
\hline $\begin{array}{l}\text { Art. } 5^{\circ} . \quad \text { Cada provincia } \\
\text { confederada dictará para sí una }\end{array}$ & Art. $5^{\circ}$. Cada provincia dictará \\
para sí una Constitución bajo el \\
Constitución bajo el sistema & sistema representativo \\
representativo republicano, de & republicano, de acuerdo con los \\
acuerdo con los principios, & principios, declaraciones y \\
declaraciones y garantías de la & garantias de la Constitución \\
Constitución Nacional; y que & Nacional; y que asegure su \\
asegure su administración de & administración de justicia, su \\
justicia, su régimen municipal, y & régimen municipal, y la \\
la educación primaria gratuita. & educación primaria. Bajo estas \\
Las constituciones provinciales & condiciones, el Gobierno \\
serán revisadas por el Congreso & Federal garante a cada provincia \\
antes de su promulgación. Bajo & el goce y ejercicio de sus \\
de estas condiciones el & instituciones. \\
Gobierno federal garante a cada & \\
provincia el goce y ejercicio de & \\
sus instituciones. &
\end{tabular}

El detalle del cambio no le pasó desapercibido a Héctor Bravo (1988, p. 65). Él advirtió la supresión de la gratuidad en el texto del artículo quinto de la redacción de 1860, pero no explicó los motivos por los cuales la constituyente de Santa Fe había sostenido en las provincias la educación elemental (en confrontación con los modelos constitucionales referidos por su texto, o al siempre citado modelo alberdiano).

\section{Un aCercamiento AL Horizonte educativo de la Confederación Argentina}

¿Cuáles fueron las posibilidades financieras de llevar adelante políticas educativas por parte de la Confederación? Las finanzas de la Confederación Argentina y sus vínculos con el Estado de Buenos Aires fueron analizados en tono de "guerra económica" por Juan lvarez (1946). Una confrontación en la que los ensayos del gobierno confederal -generar ingresos aduaneros, organizar una estructura bancaria y emitir moneda fiduciaria, bloquear o limitar los ingresos de Buenos Aires- fracasaron en forma sucesiva. A partir del balance económico que ofrecía lvarez, interrogar acerca del desarrollo educativo podría resultar improductivo. Ahora bien, el trabajo que Juan Carlos Garavaglia (2010) efectuó sobre el desempeño financiero de la Confederación revisa algunas consideraciones del planteo de ÁlvarezEfectivamente, Garavaglia detalló el papel de las deudas y la dificultad para generar recursos por parte de la Confederación; dio cuenta de la trama institucional generada a través de receptorías o aduanas, y observó algunos detalles acerca de las inversiones efectuadas con los recursos disponibles. Entre las fuentes que utiliza para dar cuenta del horizonte económico de esos años se reiteran sus referencias a memorias de ministerios o prescripciones 
del estado durante el período (leyes de presupuesto, por caso). A partir de esos datos reconstruye el presupuesto y la cuenta de gastos en la entidad en 1856 y 1858 :

TABLA 1

Presupuestos y cuentas de inversión de la Confederación, 1856 y 1858 expresados en pesos fuertes:

\begin{tabular}{|l|l|l|l|l|}
\hline Departamentos & \multicolumn{3}{l|}{1856} & 1858 \\
\hline & Presupuestos & Gasto Real & Presupuesto & Gasto Real \\
\hline Guerra y Marina & 844.232 & 1.013 .362 & 836.070 & 836.070 \\
\hline Interior & 455.357 & 459.091 & 476.627 & 476.627 \\
\hline Hacienda & 278.629 & 242.576 & 302.782 & 311.545 \\
\hline $\begin{array}{l}\text { Justicia, Culto e Instrucción } \\
\text { Pública }\end{array}$ & 244.113 & 366.603 & 173.254 & 173.254 \\
\hline Relaciones Exteriores & 39.780 & 52.310 & 73.832 & 32.667 \\
\hline Total & 1.862 .111 & 2.133 .942 & 1.862 .565 & 1.830 .163 \\
\hline
\end{tabular}

Garavaglia (2010, p. 234 ${ }^{4}$.

Además de una idea del conjunto de fondos presupuestados y gastados, la tabla detalla lo sucedido en el Departamento de Justicia, Culto e Instrucción Pública. Garavaglia destaca los porcentajes que se volcaron en este departamento. En 1856 el área recibió el $13 \%$ de lo presupuestado, y el $17 \%$ de lo efectivamente gastado. Estas cifras disminuyeron sensiblemente en 1858, con un monto de \$173.254 que, no obstante la disminución, supuso alrededor del $9 \%$ del total presupuestado y gastado (Garavaglia, 2010, p. 234).

Estas observaciones, sin embargo, no han sido acompañadas de datos que precisaran el destino de esos fondos. Así, aunque es sabido que algunas instituciones los recibían -el Colegio de Concepción del Uruguay, sobre todo-, no resultan claras distintas cuestiones, a saber: ¿en qué instituciones o actividades fueron volcados aquellos fondos? ¿Cómo se distribuyeron regionalmente? ¿Pueden reconocerse rasgos que aludan a determinada política educativa? ¿Hasta qué punto la distribución de estos recursos ayuda a comprender la lógica de los vínculos desarrollados entre provincias y estado? El análisis de un par de legajos resguardados en el Archivo General de la Nación servirá para dar respuesta a algunos de estos interrogantes y enriquecer el panorama planteado ${ }^{5}$.

Se trabajará con dos legajos de órdenes de pago. Con los registros aquí analizados es posible precisar las erogaciones efectuadas por el Departamento de Justicia, Culto e Instrucción Pública del gobierno de Urquiza. Los datos corresponden al período que va desde febrero de 1857 hasta mayo de 1860. Cada una de las entradas incluye el detalle de los pagos, el lugar y la fecha en que se dispuso el movimiento, así como la partida o el inciso correspondiente a la imputación presupuestaria. Estas órdenes fueron rubricadas por Juan del Campillo, Damián Hudson, Santiago Derqui, Alejandro Paz, entre otros. Ellos fungían como las más altas autoridades del departamento, o bien eran sus oficiales y dependientes.

Antes de comenzar el análisis de los datos cabe compartir algunas aclaraciones sobre los registros referidos. Acerca del año 1857 sólo cuenta con una entrada correspondiente al mes de enero; los años 1858 y 1859 registran imputaciones en todos los meses; y el año 1860 cuenta con entradas entre enero y mayo. Casi todas corresponden a erogaciones, pero hay algunos pocos reintegros que también han sido aquí computados. Además, al finalizar el volumen de mayo de 1860 hay media docena de enmiendas que refieren a incisos o ajustes contables que requerían ser rectificados.

El total de las inversiones en los períodos consignados por las fuentes fue la siguiente: 
TABLA 2

Órdenes de pago del Departamento de Justicia, Culto e Instrucción Pública

\begin{tabular}{|l|l|l|}
\hline Año & Pesos & Onzas en oro \\
\hline 1857 & $\$ 163.017$ & 12 \\
\hline 1858 & $\$ 223.529$ & 70 \\
\hline 1859 & $\$ 225.646$ & 100 \\
\hline 1860 & $\$ 46.242$ & 10 \\
\hline
\end{tabular}

elaboración propia sobre la base de Archivo General de la Nación (en adelante AGN) Sala X-44-9-5; AGN Sala X-44-9-6

El conjunto de las cifras, limitada a cuarenta meses, son considerables. Son cantidades mayores que las apuntadas en los presupuestos. Puntualmente, el año 1858, del cual Garavaglia refiere \$173.254 como monto presupuestado y “gasto real” (Garavaglia, 2010, p. 234), habría sido superado según las órdenes de pago aquí trabajadas en $\$ 50.275$. Así, la observación del autor al referir lo significativo que resultaba el gasto de un 8,5 $\%$ del presupuesto en el departamento podría, entonces, resultar aun remarcada. Como complemento de la tabla precedente, resulta interesante ofrecer un panorama de la distribución geográfica de dichos gastos:

TABLA 3

Distribución geográfica de las órdenes de pago del

Departamento de Justicia, Culto e Instrucción Pública

\begin{tabular}{|l|l|}
\hline Provincia & Monto en pesos \\
\hline Entre Rios / Territorio Federalizado & 495.168 \\
\hline Córdoba & 100.347 \\
\hline Salta & 20.622 \\
\hline Tucumán & 7.000 \\
\hline Mendoza & 6.000 \\
\hline San Luis & 5.500 \\
\hline Corrientes & 5.347 \\
\hline Santa Fe & 5.305 \\
\hline San Juan & 4.000 \\
\hline Jujuy & 2.500 \\
\hline Santiago del Estero & 1.500 \\
\hline La Rioja & 1.500 \\
\hline Catamarca & 118 \\
\hline
\end{tabular}

elaboración propia sobre la base de AGN Sala X-44-9-5; AGN Sala X-44-9-6

Los montos se concentran, fundamentalmente, en Entre Ríos. Las cifras aquí presentadas son significativamente más elevadas que las administradas por Urquiza hacia 1850. Pedro Serrano refiere que para el Entre Ríos de 1848 y 1850 el gasto en justicia, educación y asuntos eclesiásticos ascendía a \$ 60.639 y \$ 81.607 (citado en Mega, 2011, p. 77). Ahora, una vez sucedida la federalización del territorio se asentó en Paraná la planta de empleados del gobierno confederal. Tal como se apunta en la tabla 4, en la que se detallan los rubros erogados, era el ramo gobierno el que se llevaba periódicamente una buena parte del gasto. Pero, además, en Entre Ríos la Confederación volcaba gastos relacionados con el Colegio de Concepción del Uruguay y con escuelas elementales (se detallará el tema más adelante). En Córdoba el grueso de los gastos apuntados, \$100.347, se distribuyen entre la universidad, el Monserrat y sus estudiantes, y a los desembolsos en culto (que representan un $25 \%$ ). En un tercer escalón, con \$20.622, aparece la provincia de Salta. La mayor parte de estos fondos fueron destinados a la Iglesia. Cabe recordar que Salta, Córdoba, Entre Ríos y San Juan eran sede diocesana, cuestión que puede ayudar a explicar en alguna medida el destino de los 
fondos referidos. El caso de San Juan, sin embargo, aporta una nota distintiva: allí se destinan sólo \$4.000 en subvenciones explícitamente acordadas con el gobernador para la instrucción pública de la provincia. Las restantes provincias - Tucumán, Mendoza, San Luis, Corrientes, Santa Fe- reciben montos que rondan entre los \$ 7.000 y los \$ 5.000; Jujuy y Santiago del Estero entre los $\$ 2.500$ y \$ 1.500 , mientras que Catamarca sólo recibió $\$ 118$. Esta última cifra es apenas simbólica, pero con ella se logró una distribución de fondos por parte de la dependencia en cada una de las provincias.

Las inversiones apuntadas en estos legajos pueden catalogarse en distintos rubros. Con propósitos analíticos se han organizado en gobierno, culto, cárceles, educación, impresos y otros no determinados. Pero -dado el objetivo de este análisis-, el rubro educación se ha desglosado en elemental, colegios, universidades y estudiantes. Las sumas erogadas en ellos durante los cuarenta meses aquí tratados son las siguientes:

TABLA 4

Montos de órdenes de pago en pesos corrientes con detalle de rubros

\begin{tabular}{|c|c|c|c|c|c|c|c|c|c|}
\hline & \multirow{2}{*}{ Gobierno } & \multirow[b]{2}{*}{ Culto } & \multicolumn{4}{|c|}{ Educación } & \multirow{2}{*}{ Impresos } & \multirow{2}{*}{ Cárceles } & \multirow{2}{*}{$\begin{array}{l}\text { Sin } \\
\text { determina }\end{array}$} \\
\hline & & & Elementa. & Colegios & Universidad & Estudiantes & & & \\
\hline 1857 & 87.236 & $\begin{array}{l}\text { Sin } \\
\text { datos }\end{array}$ & 5.050 & 56.778 & 8.497 & 2.606 & 2.400 & $\begin{array}{l}\operatorname{Sin} \\
\text { datos }\end{array}$ & 450 \\
\hline 1858 & 83.459 & 30.105 & 8.873 & 86.390 & 8.158 & 949 & 1.458 & 2.727 & 1.360 \\
\hline 1859 & 90.723 & 19.159 & 7.817 & 95.528 & 6.518 & 204 & 68 & 4.264 & 1.365 \\
\hline 1860 & 9.171 & 15.412 & 3.320 & 17.892 & 0 & 51 & 0 & 248 & 148 \\
\hline
\end{tabular}

elaboración propia sobre la base de AGN Sala X-44-9-5; AGN Sala X-44-9-6.

Tal como se ha referido más arriba, el grueso de los desembolsos está en el ramo gobierno. El pago de los salarios de empleados del ministerio y el territorio federalizado de Entre Ríos constituyen la mayor parte de su volumen. A razón de unos \$ 8.000 mensuales se gastaba en tal sentido. Además había un bajo gasto en insumos administrativos (compra de armarios, muebles, útiles, tinta).

El rubro impresos incluye algunas entregas que podrían ser asociadas al ítem anterior. Tales son las propias de la impresión de memorias y registros del ministerio. Pero, además, entre dichos gastos se introducen los pagos por textos que responden a propósitos educativos. En 1857 se efectuaron dos pagos que sumaron \$ 2.300 para la impresión del catecismo de Escolástico Zegada ${ }^{6}$; en octubre de 1858 se entregaron $\$ 600$ para la compra de ejemplares del Tratado de puntuación redactado por Francisco Suárez e impreso en Corrientes $\left(\right.$ Suárez, 1858) ${ }^{7}$, y en abril de 1859 se invirtieron \$ 68 en la compra de 50 ejemplares del trabajo que Alejandro Magariños editó en Montevideo (Magariños Cervantes, 1854).

Dentro de culto se incluyen gastos que ascendieron a $\$ 64.676$ y 190 onzas de oro ${ }^{8}$. Estas últimas fueron empleadas para el pago del alquiler de la casa del delegado apostólico, Marino Marini, quien residía en Paraná desde 1857 (y por cuya casa la Confederación abonaba 10 onzas mensuales). Además se enviaron fondos para Córdoba, Salta, Tucumán, San Luis, Jujuy, Corrientes, Catamarca, Santa Fe, Mendoza y dentro del propio territorio federalizado. En conjunto se incluyen construcción y refacción de templos, pagos para ornamentos de iglesias, haberes de sacristanes o "empleados del culto", entre otros gastos.

Las inversiones en Cárcel son todas efectuadas dentro de Entre Ríos. Ascienden a \$ 7.239 y comprenden refacciones y gastos por el mantenimiento de presos.

Los desembolsos en educación se han dividido, con propósitos analíticos, en cuatro rubros: educación elemental, colegios, universidad y estudiantes. La Universidad de Córdoba había sido nacionalizada en mayo de 1854 y recibió fondos de la Confederación, pero no fueron demasiados. En los 40 meses aquí trabajados sumaron $\$ 23.173$. Esos recursos se emplearon para el traslado de profesores, sueldos, o en "gastos" o "pago al rector" (bajo una figura indiscriminada) ${ }^{9}$. 
Bajo la columna de estudiantes se incluyen los gastos efectuados en el traslado o mantenimiento de jóvenes que se estaban formando en estudios preparatorios o superiores. Los montos erogados van disminuyendo en los meses tomados en cuenta: \$2.606, \$949, \$204, \$ 51; pero no resulta sencillo deducir de tal reducción una política gubernamental. ¿Quiénes recibían tales emolumentos? León Sola se formaba en Génova, Italia, y recibió 24 onzas de oro para sus gastos (el joven era hijo de Juan León Solas, quien gobernó Entre Ríos en varias oportunidades en la década de 1820). Otro pensionado fue Fidel Cavia, de Corrientes, quien recibió montos que iban de los \$17 a los \$ 50 en una docena de oportunidades (no se han encontrado noticias acerca de dónde se formaba, pero sí se ha registrado un homónimo como jefe del departamento de estadística de Corrientes hacia 1890). Los restantes pagos, de montos menores, fueron efectuados para el traslado de estudiantes. Una vez que éstos arribaban a las instituciones en las que ingresaban como pensionados (en Córdoba o Concepción del Uruguay), ya no recibían partidas específicas y pasaban a ser mantenidos en el marco de los fondos erogados a esos establecimientos ${ }^{10}$.

El gasto en los colegios se lleva el mayor porcentaje en cada uno de los años consignados. Allí se incluyen los pocos desembolsos que superan los $\$ 10.000$ y fueron destinados tanto a Concepción del Uruguay como al Monserrat. Además se apuntan "asignaciones anuales" por montos que rondan los $\$ 2.000$ para Salta, San Luis, Tucumán y Mendoza. El conjunto de las partidas para los colegios son poco numerosas (entre 20 y 22 cada año), pero suelen exceder los \$1.000.

Algo inverso sucede con las erogaciones en educación elemental. Son numerosísimas dichas imputaciones, pero con bajos montos. Anualmente hay unas 50 entradas que tienen gastos por unos pocos pesos que se efectúan, fundamentalmente, en Entre Ríos. Las pagas que alcanzan los $\$ 1.000$ o \$2.000 son pocas (nueve). Se trata de pagos realizados a gobernadores o apoderados de distintas provincias que reciben subvenciones para el desarrollo de la instrucción elemental (San Juan, Tucumán, Santiago del Estero, San Luis y La Rioja). Acerca de este asunto, en las sesiones de la Legislatura de la Confederación, el ministro de Hacienda de Urquiza expresaba en la Cámara de Diputados el 4 de agosto de 1856: "que aunque al Gobierno Nacional no le incumbía la enseñanza primaria, debía sin embargo llenar el déficit que resultara de su instalación" (Congreso Nacional, 1886, p. 393).

Un detalle acerca de la educación elemental dentro del territorio federalizado. En 1851 Pedro Serrano publicó un breve texto titulado Riqueza Entre-Riana (algunos de cuyos datos fueron citados páginas atrás). Allí ofrece un panorama laudatorio de las inversiones realizadas por el gobierno de Urquiza. El rubro educación pública (junto a obras públicas) fue uno de los que mayores erogaciones supusieron dentro del gobierno (no se incluyen los datos referentes a los gastos militares). La inversión volcada en escuelas fue de $\$$ 21.109 a 33.499 en 1848 y 1850 respectivamente (Serrano, 1851). Es probable que allí no se hayan incluido los fondos volcados al Colegio de Concepción del Uruguay (que habían sido significativos). En lo que respecta a la educación elemental, en Entre Ríos durante los 40 meses que abarcan las órdenes de pago aquí analizadas se gastaron \$13.060. Sin dudas, ello mostró una sensible disminución que se refuerza en las palabras que Guillermo Rawson expresaría en su carácter de diputado por San Juan ante la legislatura de la Confederación en 1856:

...era un hecho constante que Entre Ríos había tenido antes mas escuelas que las que tenía en la actualidad, y que estando esta Provincia librada al Congreso, y siendo este un huésped en ella no quisiera que se comprendiese que se le escatimaba lo que debía dárseles (Congreso Nacional, 1886, p. 470).

Además de las instituciones elementales o colegios referidos, hay una escuela que, no obstante su denominación -Colegio de San Justo y Pastor-, ha sido aquí considerado como parte de las inversiones en educación elemental. Ello se debe a que dicha institución, asentada en Paraná, se abocaba a la enseñanza para niñas. Allí estuvieron concentradas todas las inversiones volcadas en la educación femenina. En total se volcaron algo menos de $\$ 6.000$. 
¿Qué muestra el conjunto de fondos erogados en educación y reproducidos en la tabla 4? El dato más relevante señala el volumen invertido en colegios. Allí se vuelcan recursos que están cerca de los desembolsados en los salarios de los empleados del gobierno -e, incluso, en algunos años superan ese rubro-, así como multiplican unas diez veces las inversiones efectuadas en educación elemental.

\section{Conclusiones}

En historia siempre resulta difícil marcar momentos de ruptura, pero parece casi innecesario justificar la trascendencia que tendría el artículo quinto de la Constitución. Aquí se enfatiza que la redacción y promulgación del artículo quinto de la Constitución de 1853 marcó un punto de referencia. Sin pretender aspirar al planteo de rasgos novedosos, se afirma que allí se cristalizó una política educativa que marcaría el desarrollo de la educación elemental argentina. Y, aunque esto parezca llamativo, no son pocos los trabajos de historia de la educación argentina que soslayan ese dato y reiteran las referencias al debate SarmientoAlberdi. Se ha mostrado, sin embargo, que no ha sido una réplica del proyecto intelectual alberdiano el modo en que ha sido redactado el artículo quinto; más bien cabe suponer que las experiencias sucedidas en el período postindependiente fueron las que le dieron sentido a su composición (Bustamante Vismara, 2016). Así, ha sido uno de los aportes de este trabajo destacar la modulación que se puede reconocer entre el proyecto de Juan Bautista Alberdi y lo sancionado en Santa Fe. Tanto acerca de las discusiones formuladas en esa Constituyente, como las que se llevarían adelante en la reunión porteña de 1860, hay argumentos sobre los que se anhelaría conocer más detalles. Lamentablemente las fuentes y los registros de esas asambleas resultan algo opacos, aunque no cabría descartar que a través de la prensa o de diferentes archivos pudieran recuperarse referencias adicionales.

$\mathrm{Al}$ realizar este análisis se ha buscado enriquecer y dimensionar las experiencias sucedidas a mediados del siglo XIX. El argumento se ha posado en una faceta más tradicional de la historia de la educación -lo prescriptivo y discutido en el ámbito constituyente-, y en un terreno mucho más esquivo: las finanzas. Si las afirmaciones de los constituyentes y las inversiones en el Departamento de Justicia, Culto e Instrucción Pública de la Confederación corren por carriles distintos, ambos forman parte de facetas que enriquecen la perspectiva que se tiene sobre los procesos educativos del período y acerca del diseño institucional.

En el envío y la distribución de fondos se advierte cierta política suprarregional. Al compás del proceso que buscó consolidar lazos e instituciones en distintas provincias se distribuyeron fondos. Se ha señalado que San Juan, Santiago del Estero, Salta, San Luis, Tucumán y Entre Ríos recibieron recursos para la educación elemental, mientras que en el rubro colegios participaron Salta, Mendoza, Tucumán, Entre Ríos y Córdoba. ¿Podría marcarse algún vínculo entre estas erogaciones, lo legislado por la Confederación en la década de 1850 y lo que Sarmiento sancionaría en 1871 como ley de subvenciones (por medio de las cuales el estado nacional se inmiscuyó con fondos e inspecciones en la oferta educativa elemental de las provincias)?

De estos datos se derivan los interrogantes que han buscado dar sentido al conjunto: ¿cómo fue pensada la política educativa de la Confederación? ¿Cuál era la orientación que se buscaba? ¿Quién o quiénes fueron los letrados que pensaron el asunto? La presencia de ciertos desequilibrios entre unos u otros gastos son rasgos que sugieren el esfuerzo de Urquiza por afirmar políticas que ya venía poniendo en marcha en Entre Ríos, con los reajustes que generó el intento de aplicar decisiones parecidas en una escala nacional. No fueron pocas las limitaciones que se advirtieron, pero parece factible considerar que cierta estructuración entre educación elemental, preparatoria y universitaria estaba siendo moldeada.

\section{RefEREnCias}

Alberdi, J. B. (1915). Bases y puntos de partida de la organización politica de la República Argentina. Buenos Aires: La cultura Argentina. 
Álvarez, J. (1946). La guerra económica entre Buenos Aires y la Confederación. En Academia Nacional de la Historia, Historia de la Nación Argentina, Tomo 8 (pp. 109-133). Buenos Aires: Imprenta de la Universidad.

Bosch, B. (1963). Urquiza, el organizador. Buenos Aires:Eudeba.

Bravo, H. (1988). Bases constitucionales de la educación argentina: Un proyecto de reforma. Buenos Aires: Centro Editor de América Latina.

Buchbinder, P. (2002). Estado Nacional y provincias bajo la Confederación Argentina: una aproximación desde la historia de la provincia de Corrientes. Desarrollo Económico, 41, 643-664.

Bustamante Vismara, J. (2016). Construcción estatal y desarrollo escolar (Córdoba, Buenos Aires y Entre Ríos, 1820-1850). Historia de la educación. Anuario, 17(1), 50-71.

Bustamante Vismara, J., y Schoo, S. (2015). Estados y educación a través de un motín estudiantil. Concepción del Uruguay, 1864. Prohistoria, Año XVIII, 24, 101-122.

Caruso, M., y Rodríguez Wehrmeister, M. (2018). Significados divergentes de lo "popular”. Sarmiento, Sastre y sus aliados en la educación primaria de la ciudad de Buenos Aires durante el período liberal temprano (1852-1872). Historia y Memoria, 7, 423-465.

Chiaramonte, J. C. (1993). El federalismo argentino en la primera mitad del siglo XIX. En M. Carmagnani (coord.), Federalismos latinoamericanos: México, Brasil y Argentina, México (pp. 81-132). Distrito Federal: Fondo de Cultura Económica.

Congreso Nacional (1884). Actas de las Sesiones del Paraná correspondientes al año de 1857. Buenos Aires: Imprenta de La Nación.

Congreso Nacional (1886). Actas de las Sesiones de la Cámara de Diputados. 1854-1855-1856. Buenos Aires: Imprenta, Estereotipía, Litografía y Encuadernación de Stiller y Laass.

Di Tella, T. S. (1969). Raíces de la controversia educacional argentina. En T. Di Tella y T. Halperín Donghi (comp.), Losfragmentos del poder. De la oligarquía a la poliarquia argentina (pp. 289-323). Buenos Aires: Ed. Jorge Álvarez.

Duarte, D. (2015). La conformación de la política educativa argentina y la crisis económica de 1873. Revista Brasileira de Historia de la Educação, 15(3), 23-52.

Escobar, N. (2010). Los funcionarios de los colegios nacionales: entre la precariedad y los enfrentamientos con las autoridades locales. 1863-1880. VIII Jornadas de investigadores del departamento de historia. Mar del Plata: Universidad Nacional de Mar del Plata.

Fernández, M. (2000/2001). Colegio Nacional y Escuela Normal: la construcción de una identidad ciudadana diferenciada. Historia de la educación. Anuario, 3, 89-112.

Garavaglia, J. C. (2010). Rentas, deuda pública y construcción estatal: la Confederación Argentina, 1852-1861. Desarrollo Económico, 50(198), 223-246.

Gorostegui Torres, H. (1972). La Organización Nacional. Buenos Aires: Paidós.

Ravignani, E. (1937). Asambleas constituyentes argentinas seguidas de los textos constitucionales, legislativos y pactos interprovinciales que organizaron politicamente la nación. Tomo Cuarto, 1827-1862. Buenos Aires: Peuser.

Halperín Donghi, T. (1982). Proyecto y construcción de una Nación, 1846-1880. Caracas: Biblioteca de Ayacucho.

Herrero, A. (2010). Una mirada sobre la educación argentina en los niveles primario y secundario entre 1862 y 1900 : las dificultades de la implantación de la enseñanza técnica y manual. Telos: Revista de Estudios Interdisciplinarios en Ciencias Sociales, 12(3), 298-322.

Lanteri, A. L. (2011). De lo ideal a lo posible. Dirigencia e instituciones nacionales en la "Confederación" (1852-1862) (Tesis doctoral). Universidad Nacional del Centro de la Provincia de Buenos Aires, Tandil, Argentina.

Lanteri, A. L. (2015). Se hace camino al andar. Dirigencia e instituciones nacionales en la "Confederación" (Argentina, 1852-1862). Prohistoria: Rosario.

Magariños Cervantes, A. (1854) Estudios históricos, politicos y sociales sobre el río de La Plata.Blondeau: Paris.

Martínez, I. (2015). Nuevos espacios para la construcción de la Iglesia: Estado nacional y sectores ultramontanos en la Confederación Argentina, 1853-1862. Quinto sol, 19(3), 1-23. 
Medina, F. (2014). Construyendo consenso y legitimidad. La proyección política del catecismo de Escolástico Zegada en tiempos de la 'confederación' argentina (1853-1862). Hispania Sacra. LXVI, 373-401.

Mega, A. (2011). La Confederación Argentina 1852-1861: ¿Un Proyecto Institucional Trunco? (Tesis licenciatura en Historia). UADER, Paraná, Argentina.

Narodowski, M. (2018). El colapso de la educación. Buenos Aires: Paidós.

Newland, C. (2014). El desarrollo de la educación elemental en Buenos Aires 1852-1862. En A. Martínez Boom y J. Bustamante Vismara (comps.). Escuela pública y maestro en América Latina. Historias de un acontecimiento, siglos XVIII-XIX (pp.287-310). Buenos Aires - Bogotá: Prometeo - Universidad Pedagógica Nacional.

Oszlak, O. (1997). La formación del Estado argentino. Orden, progreso y organización nacional. Buenos Aires: Editorial de Belgrano.

Salvadores, A. (1940). Después de Caseros. Organización de la Instrucción Pública. Paraná: Casa Predassi.

Sarmiento, D. F. (1895). Obras Completas tomo VIII. Comentarios a la Constitución. Buenos Aires: Felix Lajouane Editor.

Scobie, J. R. (1964). La lucha por la consolidación de la nacionalidad argentina 1852-1862. Buenos Aires: Hachette.

Schoo, S. (2009). Orígenes y desarrollo de la educación secundaria, normal y especial en la provincia de Buenos Aires: iniciativas provinciales nacionalizadas (1852-1920) (Tesis de maestría), Universidad de San Andrés, Buenos Aires, Argentina.

Schoo, S. (2014). Los colegios nacionales en el período fundacional del sistema educativo argentino: incidencias y variaciones locales (1863-1888). Historia de la Educación. Anuario SAHE, 15(2), 37-68.

Serrano, P. (1851). Riqueza Entre-Riana. Concepción del Uruguay: Imprenta del Colejio.

Suárez, F. (1858). Tratado de puntuación: Arreglado y dedicado a los alumnos de las escuelas de la Confederación Arjentina. Corrientes: La Opinión.

Tedesco, J. C. (2009). Educación y sociedad en la Argentina (1880 - 1900). Buenos Aires: Siglo XXI.

Zegada, E. (1857). Instrucciones Cristianas. Concepción del Uruguay: Imprenta del Uruguay.

\section{Notas}

1. Una nota acerca de la voz educación primaria. Así aparece en el texto constitucional, y cabría profundizar en los matices que esta denominación supone en este contexto en diálogo con las nociones de primeras letras, educación común o elemental. En este trabajo, sin profundizar en el asunto, se aludirá a educación primaria y elemental como sinónimos. Para este mismo período, un sugerente trabajo que indaga en los sentidos atribuidos a la noción de educación popular en la ciudad de Buenos Aires ha sido realizado por Marcelo Caruso y Marco Rodríguez Wehrmeister (2018).

2. La primera edición efectuada en Valparaíso en mayo de 1852 no contenía el proyecto constitucional, que sería agregado en ediciones posteriores.

3. La carta promulgada en Santa Fe tenía en su artículo 64 las atribuciones del Congreso, tal disposición luego de 1860 pasaría al artículo 67.

4. En este cuadro el autor, además, incluye notas con los respectivos porcentajes que representan estos valores; así como cuantifica las deudas contraídas por la Confederación.

5. Ana Laura Lanteri (2011) ha trabajado anteriormente sobre estos dos legajos en su tesis de doctorado, aunque con otra perspectiva y poniendo en valor procesos diferentes a los que aquí son apuntados.

6. La primera edición del catecismo de Zegada data de 1847, realizada en Sucre. Mientras que en 1857 se realizó una reedición a cargo de la imprenta del Colegio del Uruguay. Algunas notas y el contexto de circulación del trabajo de Escolástico Zegada pueden verse en Medina (2014).

7. Se suponía que el total a pagar ascendía a $\$ 1.200$-y por lo tanto los $\$ 600$ constituían una primera cuota-, mas no se ha encontrado el registro de un segundo pago.

8. Un análisis de las finanzas destinadas al culto durante el período puede verse en Martínez (2015).

9. Podría considerarse que este monto, relativamente bajo, se debió al hecho de que la universidad contaba con fondos propios, sin embargo, en una discusión legislativa desarrollada en Paraná en septiembre de 1856 y referida a los gastos y presupuestos del departamento, el ministro indicó que no tenía noticia precisa de los fondos con los que contaba la Universidad (Congreso Nacional, 1886, p. 470). 
10. Resta mucho por conocer acerca de la vida de estos estudiantes en los colegios, aunque no falta información en los archivos para trazar rasgos sobre ellos. Un acercamiento sobre un proceso político sucedido en Concepción del Uruguay que los tuvo como protagonistas se encuentra en Bustamante Vismara y Schoo (2015). 